The experiments showed that cadmium becomes supraconductive. This was recognised by the appearance of persistent currents, a method of observation similar to that used by Tuyn and Kamerlingh Onnes in investigating powdered substances. The same mutual inductance, which served for the measurement of the susceptibility of the salt, was used to detect these persistent currents. Extrapolation to zero measuring field gives a transition point of about $0 \cdot 6^{\circ}$.

$\begin{array}{cl}\text { Clarendon Laboratory, } & \text { N. KÜRTI. } \\ \text { Oxford. } & \text { F. SrmoN. } \\ \text { June } 3 . & \end{array}$

${ }^{1}$ P. Debye, Ann. Phys., 81, 1154 ; 1926.

2 W. F. Giauque, J. Amer. Chem. Soc., 49,$1864 ; 1927$

${ }^{3}$ W. F. Giauque and D. P. MacDougali, Phys. Rev., 43, 768; 1933. 44,$235 ; 1933$.

75 . 10. de Haas, E. C. Wiersma and H. A. Kramers, Physica, 13, $175 ; 1933.1,1 ; 1933$.

Nhy. Kưrti and F. Simon, Naturwis8., 21, $178 ; 1933$. N. Kürti, $Z$.

${ }^{\circ}$ W. Tuyn and $\mathrm{H}$. Kamerlingh Onnes, Leiden Comm., 181.

Phase Variations of Reflected Radio-Waves, and a Possible Connexion with the Earth's Magnetic Field in the Ionosphere

THE apparatus used for measuring the phase variations of the reflected radio-waves, already described $^{1}$, consists of a transmitter, modulated by the alternating 42 -cycle current to emit periodic signals of, say, $1 / 1000$ sec. duration. The receiver consists of a one-stage screen-grid high-frequency amplifier, a plate-circuit detector and a final onestage continuous current amplifier. The observations are made by a cathode ray oscillograph, the spot of which is deflected along the time axis by the same alternating current. The detector valve is made to oscillate at a frequency little different from that of the transmitter, then beat curves are observed on the oscillograms corresponding to the reflected wave trains.

The position of the beat curve is a measure of the virtual height of reflection. Moreover, when the echoes do not present phase variations (optical path constant), the beat curves are absolutely fixed; this is due to the fact that the oscillating detector is synchronous with the transmitter at the beginning of the emission of the signal. When the phase of the reflected waves changes (by variation of the optical path), the beat curves present an apparent movement, from which, as in an interferometer, it is possible to determine the velocity and the sense of the optical path variation. (For an optical path change of even a fraction of a wave-length, the modification of the beat curve is easily visible.) When the ionic density increases, the optical path diminishes, and inversely.

The most interesting phenomenon that I have observed is that the two echoes produced by the magneto-ionic double refraction sometimes present phase variations of opposite sense. This can be explained, in the present state of our knowledge, only by admitting a variation of separation of the two echoes, possibly following a change of intensity of the earth's magnetic field in the ionosphere. Whatever effects the change of ionic density, it causes optical path variations in the same sense for the two echoes. In correspondence with the periods during which I have observed phenomena of this type, even the magnetic field at the earth's surface shows remarkable variations.

Researches are in progress to investigate further the relationship between such variations in the ionosphere and magnetic conditions at the earth's surface.

"A. Righi" Physical Institute,

Ivo RANZI.

University of Bologna, Italy. May 22.

${ }^{1}$ Nuovo Cimento, p. 258, 1931. Rend. Accad. Lincei, 16, 40; 1932. NATURE, 132, 174, July 29, 1933.

\section{Radio Exploration of the Ionosphere}

Prof. Appleton's recent letter ${ }^{1}$, reporting the measurement of the magnetic intensity $H$ in the upper ionised region of the atmosphere, illustrates anew the power and value of radio methods of upperair investigation. It affords clear evidence, which probably few workers on the earth's magnetism expected ever to gain, of the decrease of the field with height. This decrease is predicted by the Gaussian potential theory, but not without some small uncertainty, due to the slight non-uniformity of the earth's magnetisation, and also to the existence of electric currents in (and perhaps beyond) the atmosphere.

Should it become possible to determine $H$ by radio methods to within 1 per cent, the results may afford a check on the magnetic theory, provided that we know also the height to which the measures refer. At present there is difficulty in interpreting the 'equivalent heights' attained by radio waves, and therefore the immediate value of Prof. Appleton's measures of $H$ may lie chiefly in the independent estimate of height which they afford, by inference from magnetic theory. In the latitude of Great Britain, and except in periods of notable magnetic disturbance, the theory seems quite adequate for this purpose. Nearer to the auroral zone, however, where the upper-air electric currents are both more powerful and more localised, the radio measurements of $H$ may become of great value in mapping the magnetic field.

Imperial College of Science, S. Chapman. London, S.W.7. May 31.

'NATURE, 138, 793, May 26, 1934.

\section{Absorption Spectra of Aldehydes}

1. RECENT observations of the ultra-violet absorption bands in the vapours of a series of homologous aldehydes have disclosed a vibrational structure, which is very similar throughout the series, since 35 measurements have given an average separation of $1025 \mathrm{~cm} .^{-1}$ in the spectra of the higher homologues, although this interval increases to $1053 \mathrm{~cm}^{-1}$ in acetaldehyde. The corresponding frequency 1187 $\mathrm{cm} .^{-1}$ in formaldehyde has been attributed to a nuclear vibration of the excited molecule $\mathrm{H} \ll \mathrm{C} \rightarrow \leftarrow \mathrm{O}$, and there can be little doubt that we are now dealing with a similar nuclear vibration $\begin{aligned} & \mathrm{R}_{K} \\ & \mathrm{H}_{K} \mathrm{C} \rightarrow \leftarrow \mathrm{O} \text { of }\end{aligned}$ the other aldehydes.

2. The maximum absorption is approximately constant at about $2900 \mathrm{~A}$. or $34,500 \mathrm{~cm}^{-1}$. In 